\title{
Development of new Lemnaceae breeding technology using Apol-humus and biogas plant waste**
}

\author{
Zdzisława Romanowska-Duda ${ }^{1}{ }^{*}$, Krzysztof Piotrowski ${ }^{1}$, Natalia Jagiełto ${ }^{1}$, Marcin Dębowski $i^{2}$, \\ and Marcin Zielinski ${ }^{2}$ ] \\ ${ }^{1}$ Department of Plant Ecophysiology, Faculty of Biology and Environmental Protection, University of Łódź, \\ Banacha 12/16, 92-237 Łódź, Poland \\ ${ }^{2}$ Department of Environmental Engineering, Faculty of Environmental Sciences, University of Warmia and Mazury in Olsztyn, \\ Warszawska 117, 10-720 Olsztyn, Poland
}

Received October 10, 2018; accepted December 21, 2018

\begin{abstract}
A bstract. Numerous possibilities of Lemnaceae use (biofuel production, supplementation of animal feed, phytoremediation, bioindication) as well as their cheap production and rapid growth offer many novel benefits. The experiment was carried out in laboratory conditions using Spirodela polyrrhiza plants. Plant cultivation was carried out in a phytotron room at $24^{\circ} \mathrm{C}$, on the liquid standard " $Z$ " medium which was supplemented with various concentrations of Apol-humus. Plant growth, chlorophyll index, net photosynthesis, transpiration, stomatal conductivity, intercellular $\mathrm{CO}_{2}$ concentration, fresh and dry weight were analysed. The obtained results indicated the beneficial effects of the addition of Apol-humus to the standard $\mathrm{Z}$ medium. The designed novel technologies were beneficial for the growth and development of Spirodela polyrrhiza and produced plants with physico-chemical parameters which surpassed those of the control. Rapid growth, a high chlorophyll index, and a far more intensive gas exchange resulted from the presence of fulvic and humic acids as well as chitosan polymers in the medium which originated from Apol-humus and of the substances originating from the waste of methane fermentation. The obtained results confirmed previous assumptions and demonstrated the possibility of obtaining increased biomass of Spirodela plants and also the possibility of using it in biogas plants and for environmental protection.
\end{abstract}

Keywords: Spirodela polyrrhiza, Apol-humus, growth, physiological activity

*Corresponding author e-mail: romano@biol.uni.lodz.pl

**This work was financed by National Centre for Research and Development in Poland, Grant BIOSTRATEG2/296369/5/ NCBR/2016 (2016-2020).

\section{INTRODUCTION}

The global economic crisis created unmatched possibilities to develop modern energy production technology based on renewable resources. An unstable oil market, political conflicts, the growth of the European population and climate change are among the major problems of the modern world. According to a document adopted by the Polish Government on the 22nd of December, 2007, the increase in the use of final energy in Poland in 2025 will exceed $50 \%$. In that case, meeting the energy needs of both individual and business entities is impossible from the economic point of view. Renewable energy is one of the main strategies of sustainable development. The electricity industry based on conventional sources of energy is becoming less and less competitive and efficient, it is very costly and harmful to the environment. According to EU commitments, Poland must increase its share of energy from renewable resources to $15 \%$ by 2020 . According to the Polish Central Statistics Office, in 2016 only 11\% of the energy used in Poland came from renewable resources. One of the most promising concepts of using renewable energy resources consists in creating agricultural biogas plants using waste biomass. The assessed amount of biogas produced from the available biomass is 5 billion $\mathrm{m}^{3}$. The potential of biogas production and its profitability depends

(C) 2019 Institute of Agrophysics, Polish Academy of Sciences (c) (1) $(9$ 
on both the availability and quality of substrates, including biomass from field production and animal breeding. A different biogas composition may be obtained depending on the substrate used to produce various post-fermentation wastes. These wastes may be used as an organic fertilizer or as a media supplement for water plant cultivation for plants such as Lemnaceae. The use of post-fermentation waste increases the profitability of substrate processing in biogas plants, moreover it remedies soil deficiencies in organic compounds. This improves soil sorption and water retention. Limiting the use of synthetic fertilizers, which are dangerous to the environment, is crucial for contemporary sustainable agriculture. The use of natural biopreparations in agriculture, favours the more effective utilization of soil nutrients, the limitation of stress factors and an increase in yields. Apol-humus contains humus acids and chitosan polymers. Humic substances occur naturally in soil, they comprise humic and fulvic acids. They have a complicated composition and are responsible for the storage of nutrients, soil structure, thermal conditions and for $\mathrm{pH}$ stabilization. They may originate from compost, peat, lignite and minerals. Due to the beneficial effect of humic acids, plants increase their intake of nutrients through an increase in the cation exchange capacity of the soil, the precipitation of calcium phosphate and plant enzyme stimulation. The effect of these substances depends on their origin, dose, application method and environmental conditions (Du Jardin, 2015). Apol-humus compounds originating from organic matter decomposition (amino acids, carbonate residues, carboxylic, methoxy, hydroxyl and amino groups) stimulate plant growth and development. Their presence intensifies the important physiological processes of plants such as respiration and gas exchange. Plants supplemented with this biopreparation are more resistant to stress and Apol-humus has a phytosanitary effect which prevents the development of pathogenic microorganisms. Chitosan is an important component of Apol-humus. In plants, it activates many enzymes, increases cell wall permeability and decreases the negative effects of harmful substances, it is an absorbent limiting pathogen development and it regulates $\mathrm{pH}$ in plant tissues. Chitosan in plants occurs in the cation form which positively influences the cation/anion balance through permanent anion binding e.g. in chlorides, nitrates. The pragmatic use of energy from renewable resources, including biomass, is one of the crucial elements of sustainable development. That is why there is a growing demand for biomass produced by plants, including Lemnaceae, which are widely used in phytoremediation and may be used to produce energy. The research was conducted to verify the hypothesis that supplementation with Apol-humus (Poli-Farm Spółka z o.o.) and waste from biogas plants will stimulate Lemnaceae growth. The aim of the research was to investigate the potential of using
Apol-humus and waste to stimulate the growth and development of the water plant Spirodela polyrrhiza and to obtain a greater yield of biomass for a multitude of applications.

\section{MATERIALS AND METHODS}

The tests were carried out in laboratory conditions using Spirodela polyrrhiza water plants, which were characterized by a logarithmic growth phase and were grown on liquid medium "Z" (Zehnder in Staub 1961). The research focused on the effects of various concentrations of Apolhumus and post-digestion effluents from biogas plants on the growth and development of Spirodela polyrrhiza. In order to determine the most favourable concentration of Apol-humus and digestate effluents from biogas plants, a wide concentration range was used in the experiment, and then each experimental variant was inoculated with the shoot members of Spirodela polyrrhiza. The experimental medium was prepared on the basis of previous results of macrophyte cultivation obtained at the Laboratory of Plant Ecophysiology. The following experimental variants were prepared: A - tap water - Control 1; B - medium " $\mathrm{Z}$ " - Control 2; C - Apol-humus 0.01\% + medium "Z"; D Apol-humus 0.02\% + "Z" medium; E - Apol-humus 0.04\% + "Z" medium; F - medium " $Z$ " + Apol-humus 0.5\%; G - tap water + Apol-humus 0.5\%; H - tap water + Apolhumus $1.0 \%$; I- liquid waste from fermentation + tap water + Apol-humus $0.5 \%$. Plant cultivation was carried out over the course of 14 days in a phytotron room at $24^{\circ} \mathrm{C}$, with constant lighting (PHILIPS MASTER TL-D2 x 18W/840). Plant growth kinetics was determined based on the number of fronds. All visible fronds were counted regardless of their surface size. The measurement of gas exchange parameters (net photosynthesis $\left(\mathrm{Pn}, \mu \mathrm{mol} \mathrm{CO} \mathrm{CO}^{-2} \mathrm{~s}^{-1}\right)$, transpiration (E, mmol $\left.\mathrm{H}_{2} \mathrm{O} \mathrm{m}^{-2} \mathrm{~s}^{-1}\right)$, stomatal conductance (Gs, mmol $\left.\mathrm{H}_{2} \mathrm{O} \mathrm{m}^{-2} \mathrm{~s}^{-1}\right)$ and intercellular $\mathrm{CO}_{2}$ concentration $(\mathrm{Ci}$, $\left.\mu \mathrm{mol} \mathrm{mol}{ }^{-1}\right)$ ) in Spirodela polyrrhiza was carried out with a TPS-2 apparatus from PP Systems (USA). The chlorophyll index content was determined using a Konica Minolta SPAD-502 chlorophylometer. The test samples were placed in an instrument clip, where they were subjected to a beam of radiation (wavelength $650 \mathrm{~nm}$ ). The device measures the amount of light absorbed by chlorophyll. On the opposite side of the light source there is a photo-detector that showed the radiation value passing through the tissue. In order to make a correction of the obtained measurement, the light (940 $\mathrm{nm}$ wavelength) absorbed by the remaining elements of the structure is measured (Pacewicz and Gregorczyk, 2009). All experiments were performed three times in 5 replicates for each treatment. Within each series, each repetition was set up in a completely randomized block design. The data obtained, provided in the form of means from replicates, were processed by applying an analysis of variance (ANOVA), using Statistica 12. The means of chosen parameters were grouped by employing Duncan's test at $\alpha=0.05$ significance level. 


\section{RESULTS AND DISCUSSION}

During the production of conventional plants for energy generation purposes various problems appear e.g. the availability of soils with an appropriate nutrient content, a reduction in crop biodiversity, the high costs of synthetic fertilizers, pesticides and herbicides, a high water demand. Water is a vital and indispensable natural resource and its value grows with increasing environmental pollution. That is why it is crucial to develop cost-efficient technologies to clean it and make it reusable (Romanowska-Duda and Pszczółkowski, 2013). The use of macrophyte-originating biomass does not require the use of synthetic plant protection products, which means an absence of water pollution, thus the water may be reused (Fedler and Duan, 2011). Water plants from the Lemnaceae family may be used for the phytoremediation of water reservoirs. They can accumulate more heavy metals and radionuclides compared to other macrophytes. The Lemna species is a hyperaccumulator and can store more than $1 \mathrm{mg} \mathrm{kg}^{-1}$ of its dry weight. Biomass from Lemnaceae plants may be also be used as animal feed. It contains significant amounts of lysine and methionine, amino acids, which are more abundant in animals than in plants (M). Lemnaceae plants have many potential applications, they can be used for biogas and biofuel production, in biorefineries, for phytoremediation and as an animal feed supplement (Romanowska-Duda and Pszczółkowski, 2013). Currently it seems promising to use water plants, mainly Lemnaceae, in biogas production as they rapidly produce large amounts of biomass, which is a perfect substrate, rich in valuable macro- and microelements (Ge et al., 2012; Romanowska-Duda et al., 2018). They can be cultivated in open reservoirs or in special lagoons. Duckweed mass doubles in 5-6 days under Polish climatic conditions, this means that $13 \mathrm{t}$ of mass may be produced from 1 hectare per year. It could be a valuable animal feed for farm animals and wildfowl (Romanowska-Duda and Pszczółkowski, 2013). Lemnaceae also accumulate heavy metals (Wechterowicz et al., 2005), municipal pollution and nitrogen and phosphorus (Mkandawire and Dudeln, 2007).

During the experiment there were 2 controls: one on the "Z" medium (Zehnder in Staub, 1961) rich in macroand microelements which are optimal for plant growth and development and the other on tap water. In the latter variant, even on the second day the effects of a lack of nutrients were visible (B). After 48-h culture, plant growth was inhibited and shoot segments were light brown, which reflects chlorophyll reduction and the lack of its synthesis. This led to plant death.

Daily observations of the morphological features and counting the shoot segments revealed that the plants reacted variously to different concentrations of Apol-humus and liquid waste from methane fermentation (Fig. 1).

The number of shoot segments was the first parameter to be analysed. During the 14-day observation period the "Z" medium supplemented with $0.5 \%$ Apol-humus produced the best results ( $12 \%$ growth). The other " $Z$ " plus Apol-humus variants $(0.01,0.02,0.04 \%)$ also produced a greater (by 2-5\%) numbers of shoot segments. For comparison, waste remaining after methane fermentation $(2 \%$ concentration) was used as the source of macro- and microelements. The mixture of liquid waste, tap water and $0.5 \%$ Apol-humus was the least effective, $85 \%$ growth inhibition was observed in comparison with the control. For the tap water and 0.5 and $1 \%$ Apol-humus variants plant growth was limited by $26-28 \%$ (Fig. 2-I).

After being cultured for 14 days the fresh weight of Spirodela polyrrhiza was measured. The variants with $0.5,0.01,0.02$, and $0.04 \%$ Apol-humus produced the best effects as compared with the " $Z$ " medium only. The mixtures of tap water with 0.5 and $1.0 \%$ Apol-humus and of $2 \%$ liquid waste and $0.5 \%$ Apol-humus were the least effective, the fresh weight was $40-50 \%$ lower compared with

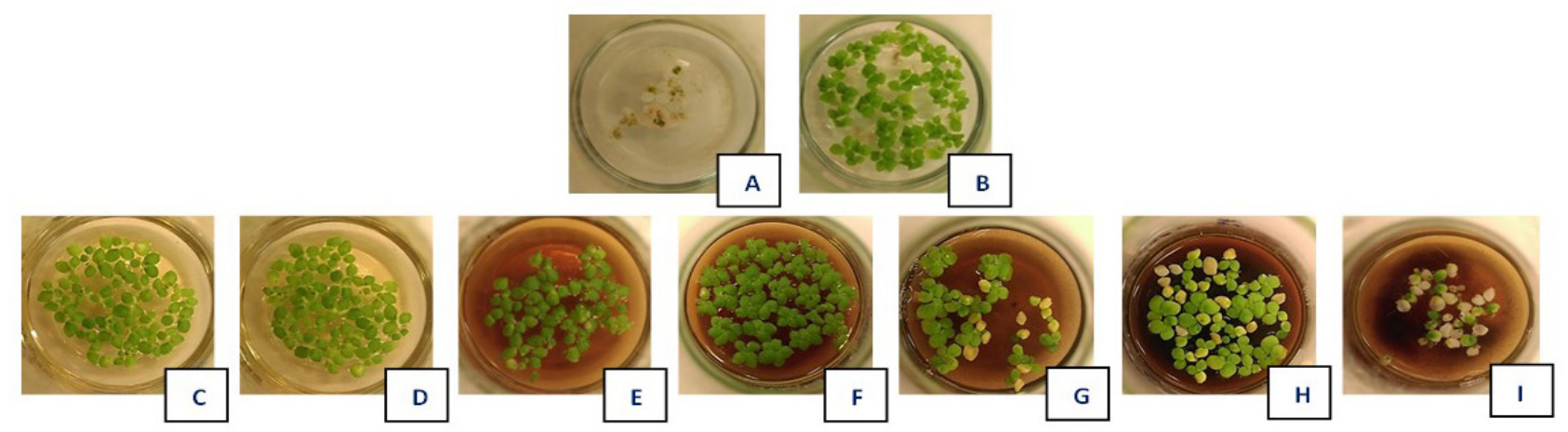

Fig. 1. Plants of Spirodela polyrrhiza L. Schleid cultivated in vitro in the presence of various concentrations of Apol-Humus, liquid media variants: Control series with standard medium „Z” (A) and tap water (B) and variants: medium „Z” + Apol-humus 0.01\% (C), medium "Z" + Apol-humus 0.02\% (D), medium "Z" + Apol-humus 0.04\% (E), medium "Z" + Apol-humus 0.5\% (F), tap water + Apolhumus $0.5 \%(\mathrm{G})$, tap water + Apol-humus $1 \%(\mathrm{H})$ and post-fermentation $2 \%+$ tap water + Apol-humus $0.5 \%$ (I). 

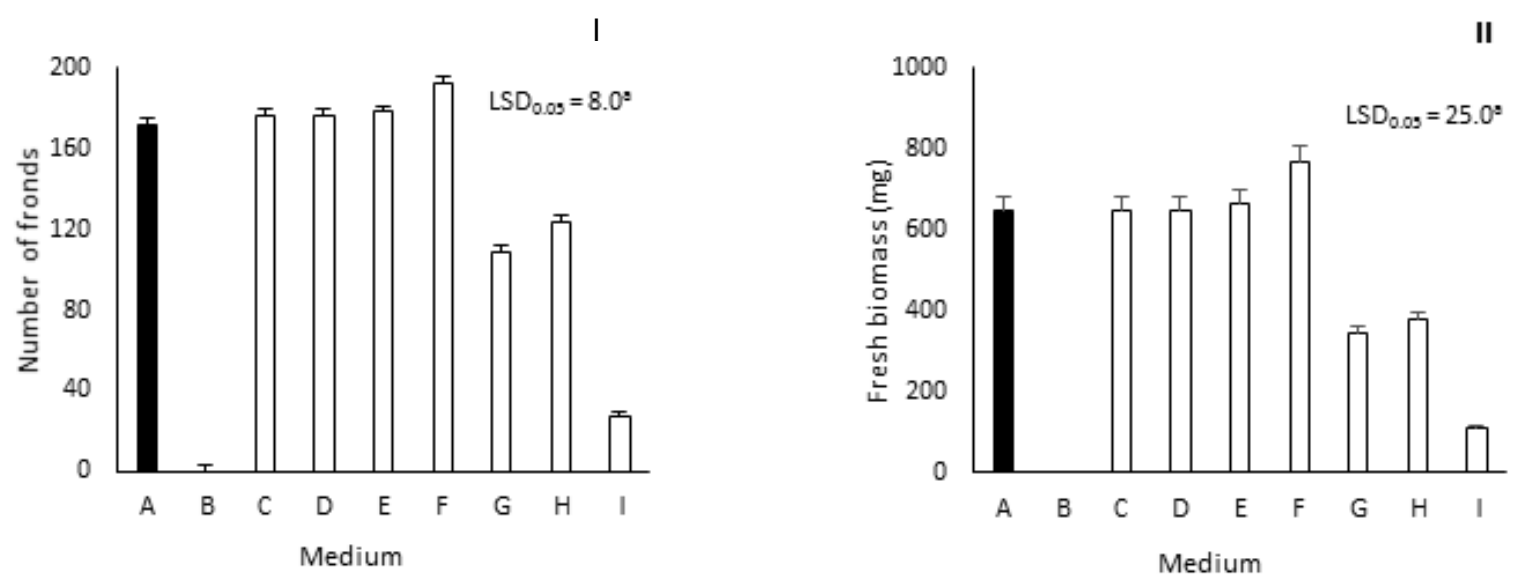

Fig. 2. Number of fronds (I) and fresh biomass (II) of Spirodela polyrrhiza L. Schleid. plants cultivated in vitro in laboratory conditions, supplemented with different variants of Apol-humus over the course of 14 days: A - tap water - Control 1; B - medium " $Z$ " - Control 2; C - Apol-humus 0.01\% + medium "Z"; D - Apol-humus 0.02\% + "Z" medium; E - Apol-humus 0.04\% + "Z" medium; F - medium "Z" + Apol-humus 0.5\%; G - tap water + Apol-humus $0.5 \% ; \mathrm{H}-$ tap water + Apol-humus $1.0 \%$; - liquid waste from fermentation + tap water + Apol-humus $0.5 \%$. Vertical bars denote \pm SE. LSD at alpha level of 0.05 .
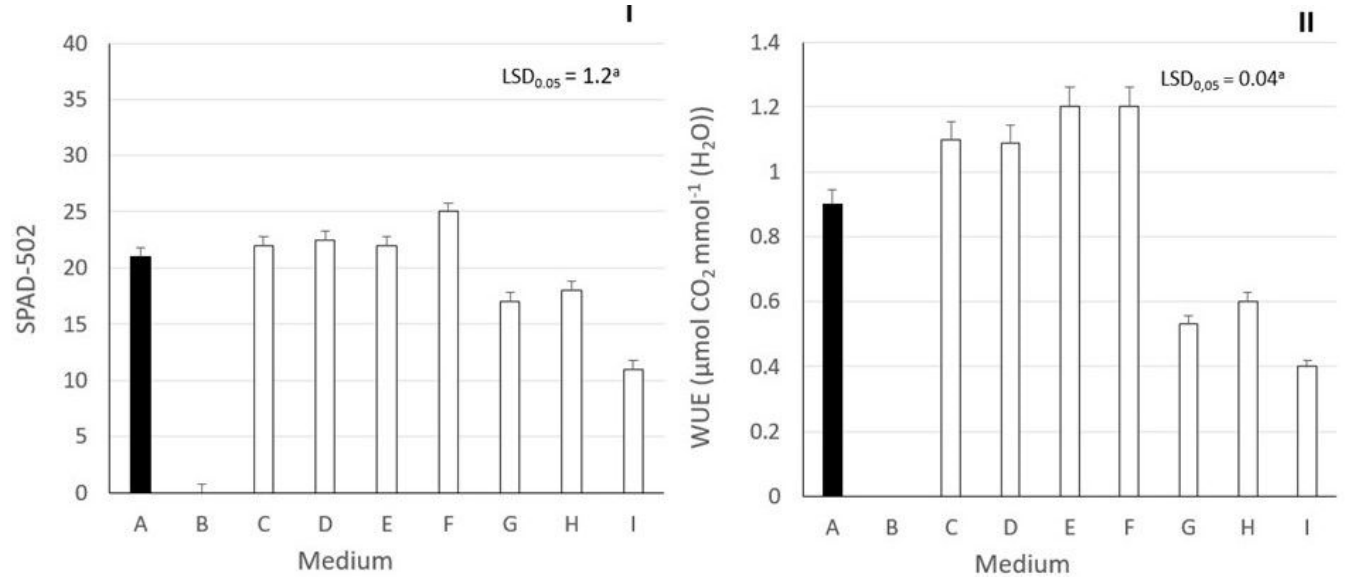

Fig. 3. Index of chlorophyll content (I) and water use efficiency WUE (II) in the fronds of plants Spirodela polyrrhiza L. Schleid. cultivated in vitro in laboratory conditions, supplemented with different variants of Apol-humus over the course of 14 days: A - tap water - Control 1; B - medium "Z" - Control 2; C - Apol-humus 0.01\% + medium "Z"; D - Apol-humus 0.02\% + "Z" medium; E - Apol-humus 0.04\% + "Z" medium; F - medium "Z" + Apol-humus 0.5\%; G - tap water + Apol-humus 0.5\%; H - tap water + Apolhumus $1.0 \%$; I - liquid waste from fermentation + tap water + Apol-humus $0.5 \%$. Vertical bars denote \pm SE. LSD at alpha level of 0.05 .

the control. The results obtained demonstrate the positive effect of Apol-humus on Spirodela polyrrhiza growth and development (Fig. 2-II).

The chlorophyll $(\mathrm{a}+\mathrm{b})$ content index and gas exchange parameters (net photosynthesis, transpiration, stomatal conductance and concentration of intercellular $\mathrm{CO}_{2}$ ) were also analysed in Spirodela polyrrhiza. The results obtained confirmed a chlorophyll content increase caused by all Apol-humus concentrations applied with the " $Z$ " medium compared with the control ("Z" medium). The best results were produced by $0.5,0.04,0.02$ and $0.01 \%$ Apol-humus variants, the chlorophyll index in shoot segments increased by $20-25 \%$ (Fig. $3-\mathrm{I}$ ). The variants with tap water and 0.5 or $1.0 \%$ Apol-humus were the least beneficial, producing a decrease in the chlorophyll index by $30-50 \%$ compared with the control. Water use efficiency (WUE) was higher in variants plus 0.5 and $0.04 \%$ Apol-humus (by $30 \%$ ) and plus 0.01 and $0.02 \%$ Apol-humus (by $21 \%$ ) compared with control. The least effective variants as far as WUE is concerned were tap water plus 0.5 and $1.0 \%$ Apol-humus, (decreases by 41 and $48 \%$ were observed) and liquid waste plus $0.5 \%$ Apol-humus, (decrease by $66 \%$ ) as compared with the control (Fig. 3-II).

Net photosynthesis in Spirodela polyrrhiza plants increased by $8 \%$ in the variants with the medium supplemented with 0.04 and $0.02 \%$ Apol-humus, the other Apol-humus concentrations had the same parameter. For the tap water, $2 \%$ liquid waste and $0.5 \%$ Apol-humus variant net photosynthesis dropped by $50 \%$ as compared with the control (Fig. 4-1). Transpiration intensity increased by 


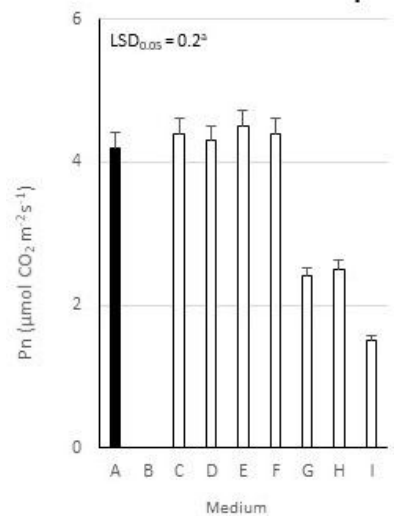

II

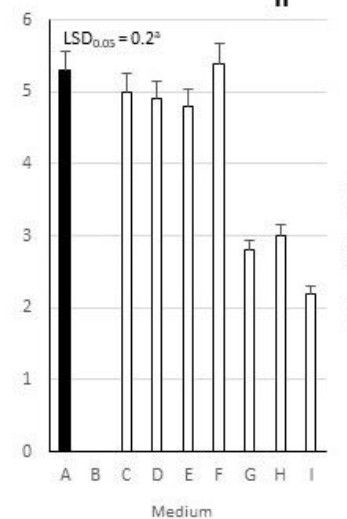

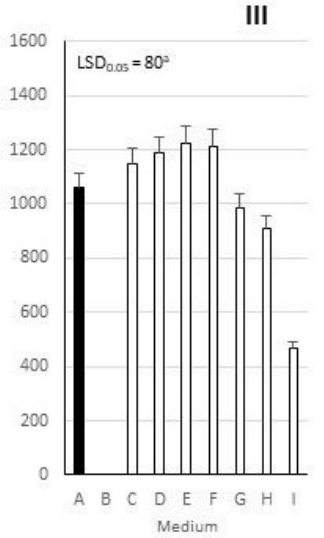

IV

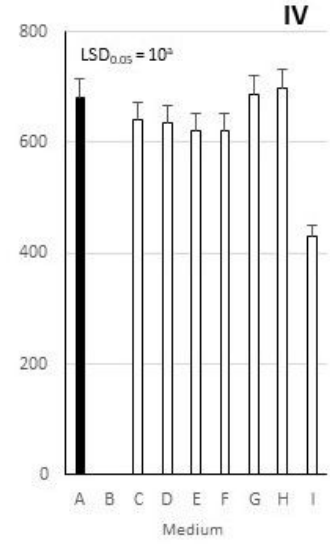

Fig. 4. Net photosynthesis (I), transpiration (II), stomatal conductance (III) and concentration of intercellular $\mathrm{CO}_{2}$ (IV) in the leaves of Spirodela polyrrhiza L. Schleid. cultivated in vitro in laboratory conditions, supplemented with different variants of Apol-humus over the course of 14 days: A - tap water - Control 1; B - medium " Z" - Control 2; C - Apol-humus 0.01\% + medium "Z"; D - Apol-humus $0.02 \%+$ " $Z$ " medium; E - Apol-humus 0.04\% + "Z" medium; F - medium "Z" + Apol-humus 0.5\%; G - tap water + Apol-humus $0.5 \% ; \mathrm{H}$ - tap water + Apol-humus $1.0 \% ; \mathrm{I}-$ liquid waste from fermentation + tap water + Apol-humus $0.5 \%$. Vertical bars denote \pm SE. LSD at alpha level of 0.05 .

$5 \%$ in the $0.04 \%$ Apol-humus variant. In the "Z" plus 0.01 , 0.04 and $0.5 \%$ variants this parameter was close to the control value. In the tap water and $1.0 \%$ Apol-humus variant transpiration dropped by $50 \%$ in comparison with the control. In the tap water, $2 \%$ liquid waste and $0.5 \%$ Apol-humus variant net photosynthesis dropped by $70 \%$ as compared with the control (Fig. 4-II). Stomatal conductance increased in all experimental variants except for the tap water, $2 \%$ liquid waste and $0.5 \%$ Apol-humus experiments, where a $50 \%$ decrease was observed as compared with the control. The highest increase (by 16\%) was observed in the "Z" plus $0.04 \%$ Apol-humus variant, increases by 14,10 and $7 \%$ were noted in "Z" plus $0.5,0.02 \%$ and $0.01 \%$ Apol-humus, respectively (Fig. 4-IIl). The intercellular $\mathrm{CO}_{2}$ concentration was increased by $20 \%$ than it was for the control in the $0.01,0.02,0.04$ and $0.5 \%$ Apol-humus variants. In the tap water and 0.5 and $1.0 \%$ Apol-humus it increased by $2-5 \%$. In the tap water, $2 \%$ liquid waste and $0.5 \%$ Apol-humus variant this parameter dropped by $40 \%$ (Fig. 4-IV).

In Poland, the use of plant biomass for energy generation surpasses other processes of energy production from renewable resources. The development of a novel, innovative technology for its production enhances the possibility of diversifying Polish sources of energy, increasing energy security and reducing greenhouse gas emissions. The choice of an appropriate plant species will result in greater biomass yield, a higher heating value and resistance to unfavourable environmental conditions. Fast-growing Lemnaceae (Les et al., 2002) provides a good alternative raw material for bioethanol production.

These plants accumulate large amounts of starch (up to $46 \%$ dry weight), contain relatively low levels of lignin (1-3\%), and can utilize a wide range of nutrients thus they can be cultivated on wastewater (Cui and Cheng, 2015; Cheng and Stomp, 2009; Basiglini et al., 2018; Pszczółkowska et al., 2019). This type of production allows for the utilization of water from sewage treatment plants thereby additionally limiting the production costs. Recovered liquid waste used for water plant cultivation may come from industrial, agricultural and municipal wastewater. The results obtained justify the use of the biostimulators, Apol-humus and of liquid waste from the fermentation of water plant culture.

The supplementation of macrophyte culture with a mixture of humic substances at appropriate concentrations is beneficial for Spirodela polyrrhiza growth and development and may be used to increase water plant yield in industrial and commercial production. There is a lot of information available concerning the use of biostimulators in water plant culture. However, there is as yet no information concerning the influence of Apol-humus over the growth of water macrophyte. Kalčíková et al. (2016) showed that the use of humic acids in Lemnaceae culture might increase chromium phytoextraction from the water environment. The presence of humic acid reduced $\mathrm{Cr}(\mathrm{VI})$ to $\mathrm{Cr}(\mathrm{III})$, which indicates that humus biostimulators may be used to remove heavy metals from water. Winck et al. (2016) described the positive effect of fertilizing Leptospermum scoparium with biosolids. The term biosolids is used with regard to a few types of treatments, which may be used as soil conditioners. Their use increased the length of plants by 9 to 13 fold as compared with the controlled ones. Moreover, Gonzga et al. (2017) and Romanowska-Duda et al. (2019) showed the positive influence of biosolids on Zea mays and Sorghum growth and development.

\section{CONCLUSIONS}

1. The results obtained demonstrated the positive effect of Apol-humus and liquid waste on Spirodela polyrrhiza growth and shoot segment development. 
2. The best effect was obtained with $0.5 \%$ Apol-humus followed by its $0.04,0.02$ and $0.01 \%$ concentrations as compared with the " $Z$ " medium control. The tested plant was highly sensitive to Apol-humus.

3. The results obtained using tap water and Apol-humus variants were similar to those obtained using the " $Z$ " medium, this confirmed the positive effect that the biostimulant had on the macrophytes.

4. The analyses of the physicochemical parameters indicated that Apol-humus increased the rate of water plant multiplication. The use of biostimulators such as Apolhumus may increase the efficiency of biomass production by the water plant, Lemnaceae. This may help to lower the costs and intensify the production of biomass, which may be a perfect substrate for biogas plants.

Conflict of interest. The Authors do not declare conflict of interest.

\section{REFERENCES}

Basiglini E., Pintore M., and Forni C., 2018. Effects of treated industrial wastewaters and temperatures on growth and enzymatic activities of duckweed (Lemna minor L.). Ecotoxicol Environ Saf., https://doi.org/10.1016/j. ecoenv.2018.01.053

Cheng J. and Stomp A.M., 2009. Growing duckweed to recover nutrients from wastewaters and for production of fuel ethanol and animal feed. Clean, 37(1), 17-26, https://doi. org/10.1002/clen.200800210

Cui W. and Cheng J.J., 2015. Growing duckweed for biofuel production. Plant Production, 17, 16-23, https://doi. org/10.1111/plb.12216

Du Jardin P., 2015. Plant biostimulants: definition, concept, main categories and regulation. Scientia Horticulturae, 196, 3-14, https://doi.org/10.1016/j.scienta.2015.09.021

Fedler C.B. and Duan R., 2011. Biomass production for bioenergy using recycled wastewater in natural waste treatment system. Resources, Conservation and Recycling, 55, 792800, https://doi.org/10.1016/j.resconrec.2011.04.001

Ge X., Zhang N., Phillips G.C., and Xu J., 2012. Growing Lemna minor in agricultural wastewater and converting the duckweed biomass to ethanol. Bioresource Technol., 124, 485-488, https://doi.org/10.1016/j.biortech.2012.08.050

Gonzaga M., Mackowiak C.L., and Comerford N.B., Flávio da Veiga Molineb E., Shirley J.P., and Guimaraes D.V.,
2017. Pyrolysis methods impact biosolids-derived biochar composition, maize growth and nutrition. Soil Till. Res., 165, 59-65, https://doi.org/10.1016/j.still.2016.07.009

Kalčíková G., Vávrová M., and Zagorc-Končan J., 2016. Seasonal variations in municipal landfill leachate quality. Management of Environmental Quality: An Int. J., 22(5), 612-619, https://doi.org/10.1108/14777831111159734

Les D.H., Crawford D., and Kimball R., 2002. Phylogeny and systematics of lemnaceae, the duckweed family. Systematic Botany, 27(2), 221-240.

Mkandawire M. and Dudeln E.G., 2007. Are Lemna spp. effective phytoremediation agents? Bioremediation, Biodiversity and Bioavailability, 1(1), 56-71.

Pacewicz K. and Gregorczyk A., 2009. Comparision values of chlorophyll content by chlorophyll meter SPAD-502 and N-tester. Folia Pomer. Univ. Technol. Stetin. 2009 Agric., Aliment., Pisc. Zootech., 269(9), 41-46, https://doi. org/10.21005/aapz2018.46.2

Pszczółkowska A., Pszczółkowski W., and Romanowska-Duda Z., 2019. Potential of Chlorella vulgaris culture for waste treatment from anaerobic biomass biodigestion at the Piaszczyna (Poland) integrated facility. J. Phycology; https://doi.org/10.1111/jpy.12856

Romanowska- Duda Z., Grzesik M., Janas R., 2019. Maximal Efficiency of PSII as a Marker of Sorghum Development Fertilized With Waste From a Biomass Biodigestion to Methane. Frontiers in Plant Sciences, 9, 1920; DOI:10.3389/ fpls.2018.01920

Romanowska-Duda Z., Piotrowski K., and Dziugan P., 2018. Utilization of Waste from Methane Fermentation in Lemnaceae Plant Breeding Intended for Energy Purposes. In: Renewable Energy Sources: Engineering, Technology, Innovation (Eds K. Mudryk, S. Werle) Springer Proc. in Energy. Springer, Cham, https://doi. org/10.1007/978-3-319-72371-6_26

Romanowska-Duda Z. and Pszczółkowski W., 2013. Lemnaceae biomass an alternative substrate for renewable energy. Acta Innovations, No 9. http://www.proakademia.eu/en/actainnovations/publications/number2013/no-9/237.html

Wechterowicz Z., Rajkowska M., and Protasowicki M., 2005. Common duckweed (Lemna minor) as a potential bioindicator of heavy metal pollution of freshwaters. Chemia $i$ Inżynieria Ekologiczna, 12(10), 1155-1161.

Winck F.V., Riaño-Pachón D.M., and Franco T.T., 2016. Advances in microalgae biology and sustainable applications. Frontiers in Plant Science, 7, article 1385. DOI: 10.3389/ fpls.2016.01385

Zehnder in Staub R., 1961. Ernährungphysiologishautökologische Untersuchung an den plank tonischen Blaualge Oscillatoria rubescens DC. Schweiz. Z. Hydrol. 23, 82-198, https://doi.org/10.1007/bf02505618 